\title{
SEXUALIDADE E FORMAÇÃO DE PROFESSORES: ALGUMAS CONSIDERAÇÕES
}

Ademir Henrique Manfré, Camila Medeiros de Araujo, Daniele Cristina Nogueira Gonçalo

Universidade do Oeste Paulista - UNOESTE, Faculdade de Ciências, Letras e Educação - FACLEPP, Presidente Prudente, SP. E-mail: camilascaioni@outlook.com

\section{RESUMO}

Este artigo é decorrente de uma pesquisa empírica inserida no eixo temático da sexualidade, voltada para a sexualidade infantil na escola. Propõe apresentar a importância da abordagem desse tema juntamente com a concepção e postura do professor diante da problemática abordada em sala de aula. Realizamos a aplicação de questionários estruturados contendo dez (10) questões abertas voltadas para a formação, considerações e atitudes dos professores que lecionam no primeiro ciclo do ensino fundamental em escolas públicas. Mediante o devido cadastro da pesquisa com o protocolo número 2768, aprovada pelo Comitê de Ética em Pesquisa (CEP), realizamos uma primeira etapa de aplicação dos referidos questionários. Apresentaremos, neste artigo, os resultados parciais de nossa investigação, bem como as categorias decorrentes da análise da primeira e segunda questão, além de uma breve discussão.

Palavras-chave: Educação. Formação de professores. Sexualidade. Escola.

\section{SEXUALITY AND TEACHER TRAINING: SOME CONSIDERATIONS}

\section{ABSTRACT}

This article is a result of an empirical research into the main theme of sexuality, toward the infantile sexuality in school Proposes to present the importance of the approach this theme along with the design and laying of professor on the topic discussed in the classroom .We carry out the implementation of structured questionnaires containing ten (10) open questions focused on training, opinion and attitudes of teachers who teach in the first cycle of basic education in public schools. By the due registration of research with the protocol number 2768, approved by the Research Ethics Committee (CEP), the application of those questionnaires. We present, in this article, the partial results of our investigation, as well as the categories arising from the analysis of the first and second issue of our questionnaire, along with a brief discussion.

Keywords: education, teacher education, sexuality, school.

\section{INTRODUÇÃO}

Esta pesquisa tem por objetivo geral investigar e apresentar a temática da sexualidade infantil na escola. Buscaremos referencial teórico em alguns autores do campo psicanalítico e dos estudos culturais sobre gênero, sexualidade e corpo. A partir de uma investigação empírica, pretendemos analisar o modo como os professores dos anos iniciais do ensino fundamental - ciclo I - entendem a sexualidade infantil na escola.

Há tempos a sexualidade é considerada como um tema polêmico seguido de vários tabus, pois a sociedade buscou, no decorrer de sua constituição, definir uma moralidade sexual aceitável comumente definindo um único significado para sexualidade. Atualmente, vivenciamos um grande impasse, já não se é possível "controlar" o surgimento das diversidades sexuais e suas manifestações (LOURO,2000 p.53). Diante do exposto, este artigo apresenta as primeiras observações de nossa pesquisa realizada por meio de levantamento de dados, acerca da concepção docente em relação à sexualidade infantil. $O$ diagnóstico parcial dessa investigação evidencia o preparo e a concepção que os docentes possuem para lidar com essa temática no ambiente escolar. 


\section{METODOLOGIA}

Optamos por uma pesquisa de base empírica, com análise de dados, os quais foram coletados em cinco escolas públicas municipais de ensino fundamental- ciclo I da região de Presidente Prudente/SP. A referida foi aprovada pelo Comitê de Ética em Pesquisa (CEP),com o protocolo número 2768 .

Algumas coletas de dados foram realizadas em reuniões de HTPC e outras individualmente nas dependências escolares. Coletamos um total de trinta questionários.

Para a realização da pesquisa, utilizamos um questionário estruturado no qual, primeiramente, coletamos informações a respeito da formação do professor, tempo de magistério, idade e em qual ano do ensino fundamental leciona. Em seguida, dez questões foram elaboradas sobre a temática proposta. Neste artigo completo nos preocuparemos com a apresentação da análise de duas dessas questões, sendo elas: 1 . O que significa sexualidade para você?, 2. Como tratar da temática sexualidade na escola?. Ressaltamos que todas as informações coletadas foram realizadas com o consentimento dos pesquisados que assinaram termoscom garantia de anonimato.

\section{RESULTADOS PARCIAIS}

Apresentaremos, neste momento, a interpretação e análise de duas questões que constam nos questionários da pesquisa. Questões analisadas:

1) O que significa sexualidade para você?

2) Como tratar da temática sexualidade na escola?

Nossa amostra contou com trinta

questionários. Em relação à primeira questão, apreendemos duas categorias interpretativas:

- Visão BIOLÓGICA da sexualidade;

- Discussão de GÊNERO.

Categorizamos como biológica as respostas em que as palavras-chave remetiam ao corpo como sendo "natural, desenvolvimento, relação sexual e afetuosa, intimidade entre casal, as diferenças entre os órgãos genitais masculinos e femininos". Observamos que, quando a palavra sexualidade é pronunciada ou vista no ambiente escolar, é automaticamente direcionada ao corpo humano tal como ele é e sua finalidade de reprodução em sua maioria. Násio $(1999$, p. 48), em seu livro $O$ prazer de Freud, retoma que"Do ponto de vista da psicanálise, a sexualidade humana não se reduz ao contato dos órgãos genitais de dois indivíduos, nem à estimulação de sensações genitais".

Em relação à primeira questão (O que significa sexualidade para você?), evidenciaramse as seguintes respostas dentro da categoria biológica: Questionário A)"algo natural que faz parte do desenvolvimento dos seres humanos".Questionário B) "sexualidade é um desejo natural que faz parte do desenvolvimento do ser humano". Questionário C) "é quando a criança começa a descobrir que seu corpo está em transformação e que seus sentimentos se tornam curiosos em relação homem/mulher e o sexo mesmo". Estas respostas apontam para questões do corpo do ser humano, de seu desenvolvimento.

Ainda na primeira questão, mas dentro da categoria discussão de gênero, evidenciaram-se as seguintes respostas: Questionário A)"O que diferencia homem mulher". Questionário $B$ )"conhecimento do corpo". Questionário C) "É tudo o que envolve questões de comportamento gênero de causa pessoal". Mesmo que se evidencie o "corpo", o gênero é independente da questão biológica (do sexo que determina feminino/masculino) e sim uma construção social e comportamental do sujeito quanto a identidade não fixa sua sexualidade(BUTLER apud LOURO, 2000b, p.28).

Em relação à segunda questão (Como tratar da temática sexualidade na escola?), analisando os mesmos 30 questionários, elencamos as seguintes categorias:

- Conhecimento do próprio corpo;

- Família em relação ensino/escola;

- Idade cronológica;

- Igualdade de direitos;

- Interesse do aluno;

- Livro didático;

- Questões curriculares.

Apresentaremos brevemente algumas respostas. Todas as categorias obtidas serão melhor discutidas na conclusão da pesquisa. Dentro da categoria "Conhecimento do próprio corpo", obtivemos as seguintes respostas: Questionário A)"De forma que a criança entenda seu corpo". Categoria "Família em relação ensino/escola": Questionário A) "conversando com a família". Questionário B) "para tratar dessa temática, em primeiro lugar conscientizar os pais e combinar maneiras de inserir claramente o assunto de forma Clara simples e Sem Rodeios". Categoria "Idade cronológica": Questionário 
A) "Com naturalidade adequada à faixa etária da criança". Questionário B) " total naturalidade, explicar da melhor forma possível e que eles vão com o tempo aprendendo o que é o ato da sexualidade". Categoria "Igualdade de direitos": questionário A) "acredito que podemos tratá-la de modo implícito destacando acima de tudo a igualdade de direitos como pessoa". Categoria"Interesse do aluno": questionário A) "Orientando a criança de forma correta em seus questionamentos sem omissões ou é necessário trabalharmos com a prevenção". Questionário B) "De forma objetiva sem mentiras ou detalhamentos desnecessários, responder pontualmente as questões da turma e utilizar tecnologia para exemplificar (vídeos)". Categoria "Livro didático": Questionário A) "o tema é sempre tratado de acordo com o que é abordado nos livros didáticos, nunca de forma aprofundada no que se diz em relação ao sexo em si, mas somente nos temas do órgãos reprodutores". Questionário B)"somente quando abordado em livros didáticos, fazendo uso do currículo escolar". Categoria "Questões curriculares": Questionário A) "acho um tema bem complicado, mas trabalho de acordo com o planejamento e o conteúdo abordado nos livros".

\section{DISCUSSÃO}

Já mencionamos as dificuldades de abordar a sexualidade na escola, ora por dificuldade da compreensão da própria terminologia, ora por não saber como inserir esse assunto na sala de aula. Há fatores externos à escola, como a família e a sociedade. Há todo um processo cultural que interfere no ensino.

Segundo Britzman(apud LOURO, 2000a), algumas questões levantadas por Robert Bastien vão ao encontro de nossa pesquisa: "será que a sexualidade muda a maneira como a professora e o professor devem ensinar ? Ou será que a sexualidade deveria ser ensinada exatamente da mesma forma que qualquer outra matéria?". Discutiremos essas questões futuramente na conclusão de nossa pesquisa com maior fundamentação teórica.

\section{CONSIDERAÇÕES PARCIAIS}

A partir da discussão direcionada nesta pesquisa, constatamos, de modo geral, que essa temática apresenta um limite: o professor ainda apresenta uma visão reduzida da sexualidade. Apenas os aspectos biológicos são levados em consideração na discussão da sexualidade na escola.

Dito de outro modo, a questão da diversidade, diferenças sexuais, prazeres sexuais, dentre outras especificações, ainda são tratadas como um tabu na escola. Desse modo, podemos afirmar que a formação do professor é fundamental para que ele mesmo tenha clareza do assunto.

\section{BIBLIOGRAFIAS}

BRITZMAN, Deborah. Curiosidade ,sexualidade e currículo. In: LOURO, Guacira Lopes (org.). O corpo educado: pedagogia da sexualidade. 2.ed. Belo Horizonte: Autêntica,2000a.

BUTLER, Judith. 0 corpo Educado: pedagogias da sexualidade.2.ed. Belo Horizonte: Autêntica, 2000.

Corpos que pesam: sobre os limites discursivos do "sexo". In: Louro, Guacira Lopes. 0 corpo Educado: pedagogias da sexualidade.2.ed. Belo Horizonte: Autêntica, 2000b, p. 151-172. LOURO, Guacira Lopes. Gênero, sexualidade e Educação: uma perspectiva pósestruturalista.6.ed. São Paulo: Vozes, 1997. NÁSIO, J.D. $O$ prazer de ler Freud. Rio de Janeiro: J. Zahar, 1999.

Recebido para publicação em 19/08/2016

Revisado em 01/09/2016

Aceito em 08/09/2016 